\title{
The Organization Theories of the Industrial Democracy Experiments Meet Contemporary Organizational Realities'
}

\section{Lars Klemsdal ${ }^{2}$}

Associate Professor, Department of Sociology and Human Geography, University of Oslo

I Johan E. Ravn

Professor, Faculty of Social Science, Nord University

I Nina Amble

Professor, Fac. of Education and International studies Oslo and Akershus University College of Applied Sciences

I Håkon Finne

Senior Researcher, SINTEF Technology and Society

\begin{abstract}
The Scandinavian industrial democracy experiments (IDEs) contained elements of organization theories, based particularly on sociotechnical systems theory (STS). In this paper, we provide an introduction to some main points of these theories and their aftermath, as a context for the six papers of the special issue on the relevance of the organization theories of the IDE for contemporary organizational realities. The six papers are also summarized and positioned in relation to the theoretical insights from the IDE.
\end{abstract}

\section{KEY WORDS}

Scandinavian industrial democracy experiments / sociotechnical systems theory / responsible autonomy / joint optimization

\section{Introduction}

he Scandinavian industrial democracy experiments (IDE) are famous nationally and regionally as well as internationally for their practical and political effective history (for instance, the working environment legislation in Scandinavia, and the globally successful Team concepts $)^{1}$. But the experiments also contain theoretical developments. A rich and manifold set of concepts and theories on organization and organizing were developed. Some of these have been in continuous use both in practical working life and in research. Others have lived a life in more obscure corridors.

The actual experiments in work reorganization began in 1964 in Norway as a joint collaborative effort between industry (Norwegian employers' organization N.A.F. and four member firms), labor (Trade Union Council LO and their locals in the same firms), and researchers (Institute for Social Research in Industry IFIM, later the Work Research Institute AFI, and The Tavistock Institute of Human Relations). The effort was known as

\footnotetext{
${ }^{1}$ You can find this text and its doi at https://tidsskrift.dk/njwls/index.

${ }^{2}$ E-mail: lars.klemsdal@sosgeo.uio.no, Department of Sociology and Human Geography, Postboks 1096, Blindern, 0317 Oslo, Norway.
} 
Phase B of the IDE project. Its later (diffusion) phases lasted well into the 1970s (Emery \& Thorsrud, 1969, 1976; Elden, 1979; Deutsch, 2005).

Our ambition in this special issue on the organization theories of the IDEs has been to explore the following questions:

- How do the organization theories of the IDEs stand as contributions to organization research and teaching as of today?

- How do these theories stand as practical and analytical tools for understanding as well as development and change of the Nordic working life as of today?

We asked these questions in an invitation to a special stream at the Norwegian Organization Studies conference (NEON) in Trondheim in November 2015, and repeated it in a general call for papers in this journal during the winter of 2016. We received several promising abstracts. After a tight deadline for full papers as well as the standard process of quality assessments through peer reviews, we are left with six papers for this special issue. These papers demonstrate how central concepts of the IDEs still provide analytical and practical starting points for analyzing and improving work organizations and - situations as of today (Amble \& Enehaug). Further, they relate central concepts of the IDE to more general analysis of traits and conditions of what we can call the late modern postindustrial working life (Thomassen et al., A and B; Madsen \& Hasle). Finally, we present an essay by one of the central actors of the later phases of the IDE and their aftermath that revisits some of the foundational questions for the survival and institutionalization of the approaches and theories of the IDE (Gustavsen).

In order to provide this special issue with due context, we take the opportunity to present an overview of central theories and features of the organization theory laying the groundwork for the IDEs, its basis in sociotechnical theory as well as some development traits after the industrial experiments faded out. It is important to note that we do not attempt to provide a comprehensive account of the IDE-experiments, nor the various lines of working life research and development that has followed in the aftermath of the IDE within the various Nordic countries. We will focus on some core elements of theories of organizations that can be extracted from the IDE-experiments, and point out some development traits that make up the context for the papers in this issue.

\section{The basis in sociotechnical theory}

The theoretical foundation of the IDE was the socio-technical systems theory (STS), developed at the Tavistock Institute of Human Relations, post Second World War. The organization theories dominating both the academic discourse and organizational practice at that time can for the sake of simplicity, be classified as Bureaucratic and Tayloristic. These approaches advanced universal principles and complete designs of organization based on specialization and coordination, as well as the reduction of the complexity of tasks to simple standard operational procedures. To put it bluntly, organizations were perceived as machines, and consequently, the workers were treated as machine parts that could be programmed to act according to the specifications of procedures (Bansler, 1989). STS was formulated in direct opposition to these approaches, challenging the idea of readymade optimal organization designs, suggesting instead

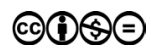


simpler designs that allowed the workers' involvement in the organizing of the working processes (Herbst, 1971). As Sitter et al. (1997) put it was this about reducing the complexity of the organization and instead increasing the complexity of the task, where the optimal building blocks of organization were envisaged as the semi-autonomous, composite groups, assigned to extended tasks in a self-organized manner. Thus, the inevitability and importance of organization principles and technology platforms in order to make organizations work was not questioned as such, but emphasis was put on the complementary importance of processes of interpretation and adaptation and enactment of formal organization and technology in practice by the organization members themselves and their local theory (Elden, 1983).

In this way, the STS approach advanced a human perspective on organization of work, but not merely from a regulation and protection perspective such as the so-called Human Relations approach allegedly did (Emery, 1993; Trist, 1981). The enhancement of the human side of work was presented not as a moral goal in itself, but as an important contributor to innovation in work and organization and measure in the optimization of the productivity and effectiveness of work. Thus, the assumption advanced and tested was that healthy, stimulating work situations would lead to worker satisfaction, and thereby commitment and loyalty to the production process (cf. Hvid et al., 2011). But just as important, this way of organizing work also took advantage of the human capacity for problem solving, the ability to manage and deal with unexpected events, thereby filling the gaps between the formal organization designs or the technology and the accomplishments of tasks.

Thus, sociotechnical theory focuses on the interface of the people and the technology of the work. This was called 'joint optimization' of the technical and the social system in the STS lingua. ${ }^{2}$ Looking back at the endeavors, Trist (1981) put forward seven significant aspects, of which he speaks of as 'a first glimpse of the emergence of a new paradigm of work in which the best match would be sought between the requirements of the social and technical system': 1 . from single jobs focus to work system; 2 . from individual job-holder to work group; 3 . from redundancy of parts to redundancy of functions; 4. from considering individuals as an extension of the machines to seeing them as complementary to the machines; 5 . from variety decreasing to variety-increasing; 6 . from external to internal regulation of individuals; and 7. from prescribed part of work to discretionary part of work.

All in all, it is clear that the theoretical ambition of STS/IDE was to account for the whole situation of people being at work. In addition, the theory also aspired to work toward a democratization of society, through the development of more autonomy and participation at work. People in narrowly defined jobs could not function as democratic actors before their roles had been changed. Autonomous work roles were seen as the basic condition enabling people to take part in society's participatory democracy. ${ }^{3}$

\section{Position and relationships in the landscape of organization theory}

Viewing the significant landscape of organization theory surrounding the IDE projects, we can see that the STS theorists were not alone in formulating their views and insights in direct opposition to tayloristic and instrumental bureaucratic theories of optimal organization. For instance, contingency theory, advancing a perspective on organization 
design as relative to the specific situational circumstances or contingencies the enterprise were facing, was formulated as a reaction toward the classical belief in one optimal way of organizing (Donaldsson, 2001). On the one hand, this was a critique that also the early phase of IDE fell prey to, however. In this phase, an important inspirational source of IDE was drawn from the Tavistock Institute of Human Relations' study of organization of coal mining in the UK after the Second World War (Trist \& Bamfort, 1951). This study demonstrated how the old way of organizing through the principles of work groups, assigned to complex tasks with autonomy to organize themselves internally, was clearly superior in terms of safety as well as productivity, to a more modern tayloristic way of organizing; the latter based on management of series of individuals, performing simpler tasks with limited responsibilities. (Trist \& Bamfort, 1951; Trist et al., 1963). From this study, the composite autonomous group was advanced as the optimal principle of organization within STS. However, as the IDE-approach developed, the importance of relating to situational contingencies when developing local work organization was increasingly emphasized. The composite autonomous group, despite its internal flexibility, was no longer considered the one best solution under changing contingencies.

On the other hand, a main point of STS/IDE was distinctly opposed to the claim of contingency theory that situational contingencies, for instance technology, tasks as well as resource availability, was constitutive and thus determinant of the design of organization. Rather, the STS/IDE strongly emphasized the potential of the human workers to develop the organization in context. Thereby one of the significant insights of the IDE projects was the importance of utilizing and providing slack or leeway within the formal organization for local learning and development processes among the employees. For instance, Herbst's notion of 'minimal critical specification design; advanced this insight when it came to designing planned change processes (Herbst, 1974). Here, the point is to make only minimal critical specifications in advance of the implementation of the plans, in order to leave it to the workers to complete the designs as they enact them in their daily work, through experimentation, improvisation, and learning processes (i.e., through processes of innovation rather than implementation) ensuring the situational fit that the contingency theorists were concerned about (Klemsdal, 2013). In this way, the IDE related more strongly to the theories on organization learning and learning organization, emerging in the second half of the ninetheen seventies, and into the eighties (Argyris \& Schön, 1978, 1996; cf Ambles paper in this issue).

It is also important to mention how the STS and IDE approaches also departed from the critical approaches of the industrial relations school, so-called labor process theory (cf Braverman, 1974) that emerged in parallel with the IDE projects. The industrial relations approach insisted on a fundamental opposition between capital and labor, constituting the society as well as the social relations at work around conflicting interests between owners and managers and workers. This was a fundamentally different position than the IDE projects took on the relation between employers and employees as reflected in ideas like joint optimization of workers situation and the productivity of the enterprise (Bansler, 1989). The concept of 'responsible autonomy' communicates the difference well. For STS/IDE, responsible autonomy, at first put forth by Trist and Bamforth (1951), then later further developed and refined by Trist et al. (2013: 21), is a design principle worth striving for. «Responsible autonomy» is by STS/IDE defined as: '(a) acceptance of responsibility for the entire cycle of operations; (b) recognition of the interdependence of one man or group on another for effective progress of the cycle, and

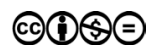


(c) self-regulation by the whole team and its constituent groups'. This can be contrasted with a view from the Labour Process theory. For instance, Friedman uses the term to denote co-optation (1977):

The responsible autonomy strategy involves allowing individual workers or groups of workers a wide measure of discretion over the direction of their work tasks and the maintenance of managerial authority by getting workers to identify with the competitive aims of the enterprise so that they will act 'responsibly' with a minimum of supervision. (1977: 48)

Responsible autonomy is understood as a managerial control strategy, based on a worker self-control grounded in a false consciousness.

Some other theory strands overlapping with or relating to the STS IDE approach must also be mentioned: ${ }^{4}$ First, there is the so-called second STS, the Science, technology and society studies/Social construction of technology (SCOT). These approaches are reading technology development as social constructions and explaining social and political processes behind the coming into being of technology (see e.g., Mackenzie \& Wajcman, 1985; Bijker et al., 1987; Latour, 1987). SCOT/STS departs from the STS of the IDE by focusing on technology coming into being more than technology put into organizational use. Secondly, there is Participatory design approach (PD), a research program that has been particularly focusing on user participation in the development of ICT technology (See, e.g., Bjerknes et al., 1987). Finally, we have the human-computer interface approach (HCI), focused on the interfaces between people (users) and computers (cf Card et al., 1983).

Leaving the discussion of other theory traditions siding with or colliding with STS/ IDE, let us now turn to how the aftermath of the IDE projects and selected aspects of how the ideas and visions have evolved.

\section{The aftermath of IDE: From principles of organization to principles of organization development and innovation and work environment research}

As argued, the IDEs were first driven on the basis of the concepts of the autonomous responsible groups, but under the more general headline of democratization of working life, that allowed for a more open and experimental attitude than merely the enactment of the responsible autonomous groups as the universal solution to problems of industrial organization. It is interesting to note that in its original approach, STS not only acknowledged the professional and semi-autonomous work communities' natural development of innovative work forms when the work group explored space and opportunities in own work situation, but it was also recognized that this set off innovations that often went under the 'engineers' radar' unless workers, managers, and other experts/researchers collaborated on identifying them, with the purpose of analyzing, documenting, and using them more generally. Such set-ups formed a necessary 'bridge' between practice and theory. The former miner Ken Bamforth, who worked at Tavistock, formed with Eric Trist such a bridge. Trist even stated that he was not 'the founder of STS, but the finder'. Trist and Bamforth (1951) brought the experiences with responsible autonomy to IDE and Norway. Today, we find this thinking in important concepts like Employee-driven innovation (Høyrup, 2010; 
Alasoini, 2011; Amelsvoort \& Hootegem, 2017) and interdisciplinary cooperative work research as, for example, action research (Gustavsen, 2014; Levin, 2017).

Thus, even though in an early phase the IDE was concerned with the general scientific ambition of generating universal theories, as Gustavsen in his contribution in this issue points out in the case of Emery and the early phase of the quality of working life (QWL) movement, still the most important theoretical development was on the local level. This point was also made strongly among the researchers following in the tradition of the IDE projects: That there was a turn away from universalistic structure oriented approaches to more process-oriented approaches focusing on development of democratic dialogues at the workplace in which participants could develop their own local theory of organization (Elden, 1983).

This represents, however, only one line of development focused on the question of enhancing the notion of democratic organization of working life by organizing for broad participation in development projects. Later, this line evolved into the organization of democratic dialogues in relation to enterprise development and still further on, development of regional development coalitions and thus more focused innovation work. Here, the partners in working life took on the task of aligning other potential development partners like universities and local government as a triple helix strategy to meet increasing global competition (Gustavsen et al., 1998, 2001).

Another line of development followed a path more focused on improving the general situation of the workers, manifested for instance in specific formulations in the Norwegian Working Environment Act of 1977, stating the psychological job requirements developed during the IDEs, as general requirements for the design of jobs in the Norwegian working life (Thorsrud \& Emery, 1970; Levin et al., 2012).

Without claiming that we account for the whole picture of the various lines of development within the Nordic working life research following in the aftermath of the IDE, we still find it tempting to ask whether the original component of 'joint optimization', central to the organization theories of the IDE, has been lost in the aftermath. That is, lost between on the one hand more instrumental innovation and enterprise development approaches, and on the other hand a more individual psychological line of work environment research in line with the human relations school, focusing on the protection and improvement of the work situation of the individual workers. Thereby, the crucial link between the two, seen by Philip Herbst $(1962,1976)$ as the core of understanding the transcendent development potential, currently appears at best to be in the peripheral vision of the research communities.

The contributions of this issue can be sorted according to the distinction just made between these two lines of development. At the same time, all contributions in their different ways make their cases for a return to the joint optimization of integrating perspectives of the work environment approach and organization approach. In the following sections, we will present the contributions of this issue more thoroughly along these lines.

\section{The work environment line}

Both Hasle et al. and the two contributions from Thomassen et al. take the work environment line of development as their main focus when addressing the significance of the organization theories of the IDE for working life of today.

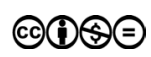


Applying an institutional optics, Madsen and Hasle identify how this work can be subsumed under two main approaches adhering to separate institutional logics: On the one hand, the enactment of nationally formulated regulations concerned with protection of the employees, and satisfying employee demands formulated on national levels, concerning Occupational Health and Safety (OHS) issues. On the other hand, approaching work environment work as a strategic issue in order to 'secure a sustainable business practice and organizational outcomes', as found within HRM strategies.

While acknowledging that OHS approaches and HRM approaches are increasingly integrated within specific work environment practices, their contribution is to identify how these approaches still adhere to two separate institutional logics creating potential tensions within work environment practices. This can also explain the tendency of variations among organizations in how they approach their work with working environment issues.

In two contributions to this issue Thomassen, Heggen, and Strand address how large parts of the Nordic working environment research as of today suffer from a tendency toward a more individualized focus on the protection of the individual as a psychological being. The problem is that issues relating to the protection of the workers as well as concerns with QWL tend to become matters of the individual workers as a psychologic and physiologic being, rather than as a matter of working conditions as such. The focus moves from the organizational environment of the workers to the workers themselves.

For instance, in the article 'Exploring the concept of Integrity - Toward a CraftInspired Interpretation', Thomassen, Strand, and Heggen propose that a fruitful development would be to reintroduce the organization and the collective as the unit of analysis as well as focus of development or improvement work in working life. They address how the concept of integrity has become an important measure for the quality of work within work environment research of today, for instance manifested by a separate paragraph concerning this issue in the Norwegian working environment act of 2005. However, supplementing the dominant psychological notion of integrity with what is characterized as a sociological notion of integrity is suggested, drawing on Richard Sennet's concept of professional integrity in craftsmanship. While the psychological notion of integrity addresses the individual workers' stressful experience of inability to act coherently, or in line with personal beliefs, a collective notion of integrity will refer to professional collectives and their in/ability to maintain their professional collective practices - their craft in the face of external demands challenging their integrity. This extension resonates with the industrial democracy project's more holistic approach to analysis and improvement of work situations, perceiving the quality of work as both a matter of psychological experiences and quality of performances and their products. It thus promotes a view of work place development that address the organization of task performance and contingencies of work processes, as the precondition for professionals' experience of integrity, rather than measures protecting the individual from being exposed to psychological stress by incompatible expectations. We are reminded of Herbst's notion that the product of work is people - and not that people are fixed entities who just happen to be exposed to damaging influences on their psyche in the workplace.

A somewhat related point is advanced in their other article 'Sociotechnical Systems as an Inspiration for Working Environment Research in Second Modernity - Opportunities and Need for Renewal'. In this article, Thomassen, Heggen, and Strand (2017) find that the Nordic working environment research, evolving from the STS and IDE tradition, has matured into a field of its own. While being transformed into OHS research, 
it has lost the organizational perspective out of sight. Where it once stressed social reform, it now takes on a highly individualistic and psychological approach. Instead of social reform, there is therapy. As an alternative, the authors propose to reintroduce the organizational and systemic focus. As they argue, 'poor conditions will indicate a need for technological, systemic, and organizational change-and not a change in the subject'. They proceed to take Beck's analysis of 'risk society' and the second modernity as a point of departure to investigate whether and how the STS approach can address the contemporary questions of work life, namely the 'second modernity risks'. These are multidimensional, horizontally distributed, paradoxical, implicit, and (often) individual, with complex and unclear solutions. Wrapping up their discussion, they conclude that although some of the preferred organizational solutions of STS, such as 'worker autonomy', may not cope well with present day challenges such as selfexploitation, it still is the case that 'questions of organizing' are important to address in working environment research. STS, renewed, by reflexivity and double hermeneutics, is therefore needed.

\section{The organization development line}

Thus, Thomassen et al. also touch upon how one of the central founding ideas of the sociotechnical systems school, the idea of responsible autonomy, backfires in the context of the so-called postindustrial work life, by being more about internalizing measures of control and self-control, and responsibility in the individual worker, actualizing the critique by the Labor process theory, mentioned above. In this way, the STS theories and concepts can be accused of losing their emancipatory, liberating potential and instead become turned into a vehicle for new forms of oppressions during the late modernity or postindustrial work life. If we turn toward Enehaug's article in this issue, the notion of responsible autonomy appears as still liberating, however now employed within an organizational development context, and thus related to the other separate line of development from the IDE, mentioned above.

In the paper, Ten successful years: A longitudinal case study of responsible autonomy and organizational learning, Enehaug describes a company's walk from a Lysgaardian work orientation, characterized by mistrust and a dysfunctional cooperation, to a situation of responsible autonomy. Responsible autonomy is described as a collective phenomenon distinguished by the employees' acceptance of responsibility for the entire cycle of operations, which is recognition of the interdependence of one person or group on another for an effective progress of the cycle and a self-regulation by the entire team and its constituent groups. Through such a status on operations, the workers were able to distribute the strain of work and gain buffers against stops in production, in a social manner.

Thus, in this case, we experience a return to the classical principles of STS, the principle of responsible autonomy (Trist et al., 1963), translated in the IDEs as 'relatively or semi-autonomous groups' or 'relatively self-regulated groups' (Thorsrud \& Emery, 1970).

The new, and possible paradox, is how the toolbox of lean production became helpful in the development process of the collective autonomy. Enehaugs contribution is bridging work environment research and STS' focus on primary work tasks, clarifying a new dimension to work environment research. This dimension goes from Karasek and Theorell's (1990) individual autonomy to lifting forward the work environment

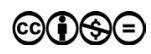


dependence on a collective component. By this, the author is contributing to a more developmentally oriented, collective autonomy concept.

Organizational learning, or the learning organization, founded on Herbst's notions of minimal critical specification design and slack, is the topic of Amble's article 'A Learning Organization in Practice: Service Development in Care Work'. Probably not known to all, Herbst, one of the pioneers of the IDE, also developed a concept of the learning organization. This is not the best known part of the IDE endeavor. So much the better that Amble brings it forth and uses it in an analysis of a contemporary 24-7 continuous work organization in public care. Her article discusses how the introduction of working with a new service concept, so-called 'everyday rehabilitation', became a commonly created process, by a learning organization.

The literature on organizations and learning is vast. The two dominant directions in it are set off by Chris Argyris and Donald Schön $(1978,1996)$ and 'organizational learning', and Peter Senge and 'the learning organization' (1990). Amble's argument is not primarily that Herbst anticipates the other organizational learning theorists, but that he brings forth a different concept. Treated by Amble, the concept is informed by other STS ideas as well, most notably the idea of minimal critical specification and the principle of broad participation, but Amble also introduce the theory of job crafting (Wrezniewsk \& Dutton, 2001) into the concept. By this, she develops a concept of a learning organization with better antennas for the experiments and learning taking place in the micro processes in work.

Amble discusses a multidimensional (matrix) learning system within an organization that is situated in the everyday practices of the work organization itself, not staged or strategically managed, that runs as a continuous flow, and where 'knowledge and experience are brought back and forth between sections and units', supported by minimal critical specification and responsible autonomy.

\section{The diffusion:The improvement of working life as a social movement}

Finally, one of the important ambitions of the IDEs was not only the improvement of the enterprises involved in the experiments. Rather, as a research program, the aim was to develop valid knowledge about optimal ways of organizing work in general, and spread these insights to the rest of the society, both nationally and globally. The editors have invited prof. em. Bjørn Gustavsen, grand old man and alma pater of Scandinavian working life studies, to reminisce on the rise and fall of the international QWL movement, which was an international effort to create a movement for spreading the insights of sociotechnical systems research, including the experiences from the IDEs in Scandinavia. This movement was initiated by and had the major figures in STS research as members. Gustavsen has set his mark on research and development in and on working life in Sweden and Norway for several decades and counts as one of the fathers of the change in Norwegian work environment legislation in 1977 to mandate employee participation in daily decisions and development issues. His article is based on participant observation of the QWL Movement.

QWL was a researcher-driven social movement that came into being in the 1960 s, based on people engaged in industrial democracy and work reforms aiming at 
humanizing the workplace. The movement mainly spans not only Europe and the US but also Australia and Japan, and its active membership culminated in the early 1980s. Its 1981 conference had some 2000 participants from research, management, unions, and government from about 30 countries. Their unifying idea was that the kind of workplace organization demonstrated in the IDEs in Norway (and elsewhere) had an emancipatory potential for democracy, productivity, and health in the workplace and beyond. Except how could this transformation take place on a large scale?

Gustavsen does not present a nostalgic picture of what could still have been a great movement with a significant impact but rather an epistemological analysis of why the whole movement withered away following a critical event. If we read him correctly, most researchers had inherited the scientistic notion of a unified theory as that which would carry society to what in today's parlance might be called 'the next level'. However, as Fred Emery - one of the main architects behind this unified theory - put it, the theory would not operate primarily through specifying solutions to problems but rather through driving a social movement. Emery and others around the Tavistock Institute had long since moved from the idea that there are some sociotechnical optimal solutions to particular production problems, and into the idea that it is the participatory qualities of the process of solving these problems, that count. Nevertheless, their entire body of contributions to organization theory, applying a general systems theory approach, tacitly assumed understanding proper change processes as 'a linear transformation emanating from a common point of departure, so that the notion of one movement representing one single general reason could be maintained', to quote Gustavsen. This entire foundation was blown up in a single event in 1987, where about 50 core members of the movement met with Gareth Morgan's multiperspectivation take on organizations. ${ }^{5}$ Wither modern theory, even in its collective and emancipatory form; hello postmodern construction and deconstruction of contextually bound meaning.

Except, Gustavsen argues sociologically that the existence of a strong theoretical umbrella (still) is a must for a body of researchers to maintain a viable community to do what really matters, which is to test out knowledge claims systematically in the field, where new knowledge is 'co-generated'6 in the form of local theory. Without such a web of professors and journals, and a proper publication record, the legitimation for doing the ever-important field work is waning. And, mind you; field work is not primarily for testing theoretical claims but for doing what unified theory failed to achieve: to be the driver of the social, transformative movement.

The constitution of social ensembles of research, management, employees, unions, and government to cogenerate what neither a general theory nor a social movement managed to do in the wake of the Norwegian IDEs, has been a leitmotif for Gustavsen in all his work. We thank him for divulging some of its origins and invite others to join in the reflection.

\section{And last, a small note on Technology}

An important cause for the original social-scientific interest in the industrial organization and the industrial democracy projects was the introduction of new manufacturing technologies into work organizations, notably various forms of (early) automation. The attention to technology by IDE/STS was not the first (or last) time that technological 
change in manufacturing industry was subject to research. ${ }^{7}$ Relevant new STS research in this domain is also in progress but unfortunately not available at this time for this special issue. However, we still spend some time reflecting on the usefulness of STS and IDE confronting the present technological revolution: Following the journals as well as the daily news today, we are faced with what appears as a major technological revolution, a 'new technology wave', with massive introductions of 'game changers', such as robotics and digitalization. Parts of this technological developments are categorized under the term 'Industry 4.0' (Berger, 2014; Lasi et al., 2014), referring to the current trend of reshaping industry - and society - by use of a whole set of new interconnected technologies, such as robotics, automation, network sensors, data exchange, cloud computing, and the Internet of things. Some have termed this 'a fourth industrial revolution' (Schwab, 2016), referring to modern manufacturing taking place in 'smart factories' that are based on real-time interconnectedness, cyber-physical systems, and decentralized and partly automated decision-making.

There is a lot of anticipation about how these new and complex interconnections of physical machines, software, big data, and Internet, and on how the fusion of industry, ICT, and logistics will lead to major changes in business models, production processes, skills needs, and forms of cooperation. And so on.

There is also a lot to the observations and assumptions above. In many ways, they are probably both correct and important. But it should also be noticed that the present discourse on Industry 4.0 conveys a rather heavy lopsidedness toward 'technological determinism': the assumption that technology development follows its own path, relatively independent of the sociocultural or political circumstances, and that technology determines the societal (Winner, 1980; Mackenzie \& Wajcman, 1985). Historically, ever since Marx, this has been the most dominant perspective.

In contrast to this, a vital principle or axiom underlying the sociotechnical originals and the ID experiments, from which they spun their theories and concepts, was that the organization facing new technology is not facing inevitability, but choice. STS/IDE did not treat the 'technical system' as something that the 'social system' just had to take as a given, and adjust accordingly to, but held a dual perspective: The technical and the social system is mutually constitutive.

Thus, when facing the present situation, with all its discussion of digitalization, automatization, computerization, the way ahead toward the future may seem given and inevitable. Precisely here and now, before everyone enters the same trajectory, it may seem wise to introduce a complementary set of concepts and theories about technology and organization to import into these situation analyses. Not in order to arrest or contradict the prevailing discourse, but rather to supplement it. Pragmatism used to be one of the characteristics of the ID program.

That might be good advice for this project as well. It is our intention that this issue can be a contribution to thinking a bit broader, a bit wiser, and a bit less deterministic about the way ahead for technology and work organizations, in order to curb unrest and in order to widen the perspective of the possibilities. In order to do this, we hope to see studies that relink the research strands of worker well-being and production development given the opportunities awarded by the new technology wave. As Gareth Morgan (1993) underlines a key learning point from Eric Trist: 'the introduction of new technologies always presents an occasion for organizational choice' (1993: 355). 


\section{Conclusion}

What then, seems to be the important 'take aways' from the organization theory of the IDEs, for our contemporary organizational realities?

The initial strong contribution from the IDE was the alternative organization theory. This includes the focus on the interplay between social or human and technical systems when analyzing and designing work organizations. It also includes the emphasis on the importance of ensuring the quality of work of the workers as a goal in itself, as well as an important means for securing the quality and productivity of the output of the production process and its development.

A central concept within this organization theory is the concept of responsible autonomy. As mentioned, this is a normatively more ambiguous concept in the late modern postindustrial working life working life than it was in the 1960 . The concept of Workers autonomy have a different meaning as well as practical implications in the context of individualized postindustrial knowledge work, where the employees are doomed to a kind of autonomy and responsibility, than it had and have in the context of industrial working life. However, the relevant lesson from the IDE for our present day postindustrial organization is the emphasis on establishing responsible autonomy on a collective level rather than at the individual. This is for instance offered by the notion of the semi-autonomous, self-regulating group assigned to complex tasks, finding in its own self-regulated work a source of collective innovation, complemented by various forms of lasting and temporary network and matrix organizations suitable particularly for development or transformation or innovation. This is an alternative to the modern conception of the highly specialized complex organization, consisting of individual, individualized employees.

The tendency toward individualization of working life, finds however, its parallels in work life research as well, where the focus on the well-being and QWL addresses the individual rather than the collective level. Particularly within the OHS research, a focus on organization of work and the collective level rather than the individual, which is the prevalent as of today's research, seems like a promising strategy to moderate the tendencies toward individualization. Thus, revisiting the IDE reminds us of the constructive and emancipating potential in research addressing the collective level as the unit of research as well as of development work.

Further, the IDE on the basis of STS offers a perspective on technology not as replacing the workers, thereby reducing the workers' role in the production process, but a perspective emphasizing the fruitful interaction of technology and human labor, and subsequently, the importance of involving the workers in the development and implementation of the technology. Philip Herbst concept of Minimal critical specification deserves a special mention here: As digitalization and automation continues, employee roles may become more like herders of robots and overseers of technological systems who in themselves are able to adapt and change. A 'maximum' specification of such systems in their entireties seems more and more unlikely to achieve. Thus, minimal critical specification still seems a promising principle - but what does it imply in such settings?

Finally, IDE demonstrates the possibility and fruitfulness of democratization of working life, emphasizing the importance of the workers influence in the organization of performance of tasks as well as in development of the organization, for motivation, innovation, and well-being in work organizations. In short, joint optimization. 


\section{References}

Alasoini, T. (2011). Workplace development as part of broad-based innovation policy: Exploiting and exploring three types of knowledge. Nordic Journal of Working Life Studies, 1(1), 23-43.

Argyris, C. and D. A. Schön (1978). Organizational Learning: A Theory of Action Perspective. Reading, MA: Addison-Wesley.

Argyris, C. and D. A. Schön (1996). Organizational Learning II: Theory, Method and Practice. Reading, MA: Addison-Wesley.

Bansler, J. (1989). Systems development research in Scandinavia: Three theoretical schools. Scandinavian Journal of Information Systems, Vol 1 (1): 3-20.

Berger, R. (2014) Industry 4.0. The New Industrial Revolution. Roland Berger Strategy Consultants

Bijker, W. E., T. P. Hughes and T. Pinch, Eds. (1987). The Social Construction of Technological Systems. Cambridge, MA: MIT Press.

Bjerknes, G., P. Ehn, M. Kyng and K. Nygaard. (1987). Computers and democracy: A Scandinavian challenge. Gower Publishing Co.

Braverman, H. (1974). Labor and Monopoly Capital: The degradation of work in the twentieth century, New York: Monthly Review Press,

Card, S. K., P. Moran and A. Newell (1983). The Psychology of Human-Computer Interaction, Hillsdale, NJ: Erlbaum.

Chandler, A. D. (1973). Strategy and Structure: Chapters in the History of the [American] Industrial Enterprise. Cambridge, MA: MIT Press.

Deutsch, S. (2005). A Researcher's Guide to Worker Participation, Labor and Economic and Industrial Democracy. Economic and Industrial Democracy 26(4): 645-656. doi: http:// dx.doi.org/10.1177/0143831X05057505.

Donaldsson, L (2001). The Contingency Theory of Organizations. Thousand Oaks, CA: Sage

Elden, M. (1979). Three generations of work-democracy research in Norway: beyond classical socio-technical system analysis. The Quality of Working Life in Europe. In C. L. Cooper and E. Mumford. London, Associated Business Press: 226-257.

Elden, M. (1983). 'Democratization and participative research in developing local theory.' Journal of Occupational Behaviour 4(1): 21-34.

Elden, M. and M. Levin (1991). Cogenerative Learning. Bringing Participation Into Action Research. Participatory action research. W. F. Whyte. Participatory Action Research. Newbury Park, CA: SAGE Publications: 127-142.

Emery, F. (1964). Reports on the Hunsfos project, London.

Emery, F. and E. Thorsrud (1969). Form and content in industrial democracy. London: Tavistock.

Emery, F. and E. Thorsrud (1976). Democracy at Work. Leiden: Martinus NijhoffFriedman, A. (1977). 'Responsible Autonomy versus Direct Control over the Labour Process.' Capital and Class 1: 43-57.

Gustavsen, Bjørn (2014). Social impact and the justification of action research knowledge. http://arj.sagepub.com/contenet/early/2014/05/11/1476750314534455. doi: http://dx. doi.org/10.1177/1476750314534455.

Gustavsen, Björn, Tom Colbjørnsen and Øyvind Pålshaugen (eds.) (1998). Development coalitions in working life. The 'Enterprise Development 2000' program in Norway. Amsterdam: John Benjamins Publishing Company.

Gustavsen, Bjørn, Håkon Finne and Bo Oscarsson (eds.) (2001). Creating connectedness. The role of social research in innovation policy. Amsterdam / Philadelphia PA: John Benjamins.

Gustavsen, Bjørn and Gerry Hunnius (1981). New patterns of work reform. The case of Norway. Oslo: Universitetsforlaget. 
Eijnatten, F. M. v. (1993). The paradigm that changed the work place. Assen, The Netherlands: Van Gorcum.

Herbst, P. G. (1962). Autonomous group functioning. An exploration in behaviour theory and measurement. London: Tavistock.

Herbst, P. G. (1971). Utviklingen av sosio-teknisk analyse. In Herbst, P. G (ed) Demokratiseringsprosessen $i$ arbeidslivet. Oslo: Universitetsforlaget [The development of socio-technical analysis.]

Herbst, P. G. (1974). Socio-technical Design: Strategies in Multi-disciplinary Research. London: Tavistock Publications.

Herbst, P. G. (1976). Alternatives to hierarchies. Leiden: Martinus Nijhoff.

Hvid, H., Bergholm, T., Gonäs, L., Juul, I., Kamp, A., Karlsson, J., Kasvio, A., Klemsdal, L., Salomon, R. and Skorstad, E. (2011). Editorial: Nordic working life research-Continuity and renewal. Nordic Journal of Working Life Studies, 1: 3-21. doi: http://dx.doi.org/10.19154/ njwls.v1i1.2333.

Høyrup, S. (2012). Employee-driven innovation: A new phenomenon, concept and mode of innovation. In S. Høyrup, C. Hasse, M. Bonnafous-Boucher, K. Møller, \& M. Lotz (Eds.), Employee-driven innovation: A new approach (pp. 3-33). Basingstoke and New York: Palgrave Macmillan.

Klemsdal, L. (2013). From Bureaucracy to Learning Organization: Critical Minimum Specification Design as Space for Sensemaking. Syst Pract Action Res 26(1): 39-52. doi: http:// dx.doi.org/10.1007/s11213-012-9267-3.

Knutstad, G., T. Nilssen \& M. P. Buvik. (2009). Sosioteknisk systemteori - en gjennomgang av vekst og utvikling. Trondheim, SINTEF. [Socio-technical systems theory: - an overview of its evolution]

Lasi, H., Fettke, P., Kemper, HG. et al. (2014). Industry 4.0. Bus Inf Syst Eng 6 Issue 4, pp. 239-242. doi: http://dx.doi.org/10.1007/s12599-014-0334-4.

Latour, B. (1987). Science in Action. Cambridge, MA: Harvard University Press.

Levin, Morten (2017). Aksjonsforskning som forskning - epistomologiske og metodiske utfordringer. In Gjøtterud, Hiim, Husebø, Jensen, Steen-Olsen and Stjernstrøm (eds.) Aksjonsforskning $i$ Norge: Teoretisk og empirisk mangfold (pp. 27-45). doi: https://doi.org/10.23865/ noasp.17. [Action research as research - epistemological and methodological challenges]

Levin, M., T., Nilssen, J. E., Ravn And L., Øyum. (2012). Demokrati I arbeidslivet. Bergen: Fagbokforlaget [Democracy in working life].

Mackenzie, D. and J. Wajcman, Eds. (1985). The Social Shaping of Technology. London: Open University Press.

Morgan, G. (1986). Images of Organization. Beverly Hills, CA, SAGE Publications.

Morgan, G. (1993). Organizational Choice and the New Technology. In E. Trist and H. Murray (Eds.) The Social Engagement of Social Science - A Tavistock Anthology. Philadelphia, University of Pennsylvania Press: 354-368.

Mumford, E. (1997). 'The reality of participative systems design: contributing to stability in a rocking boat.' Information Systems Journal 7: 309-322. doi: https://doi.org/ 10.1046/j.1365-2575.1997.00020.x.

Schwab, K. (2016). The Fourth Industrial Revolution. World Economic Forum. ISBN 1944835008.

Senge, P. M. (1990). The Fifth Discipline. The Art \& Practice of The Learning Organization. New York, Currency Doubleday.

Sitter, L. U. de, Hertog, J. F. den and Dankbaar, B. (1997). From complex organizations with simple jobs towards simple organizations with complex jobs. Human Relations, vol. 50 (5): 497-534. doi: https://doi.org/10.1177/001872679705000503.

Smith, M. R. and L. Marx, Eds. (1994) Does Technology drive History? Cambridge, MA: The MIT Press. 
Trist E. L. and Bamforth K. W. (1951) Some social and psychological consequences of the Longwall method of coal-getting: An examination of the psychological situation and defences of a work group in relation to the social structure and technological content of the work system. Human Relations, 4(1): 3-38. doi: https://doi.org/10.1177/001872675100400101.

Trist, E. L., G. W. Higgins, H. Murray and A. B. Pollock. (2013 (1963)). Organizational Choice. Capabilities of groups at the coal face under changing technologies. The loss, re-discovery and transformation of a work tradition. London: Routledge.

van Amelsvoort P., Van Hootegem G. (2017). Towards a Total Workplace Innovation Concept Based on Sociotechnical Systems Design. In: Oeij P., Rus D., Pot F. (eds) Workplace Innovation. Aligning Perspectives on Health, Safety and Well-Being. Cham: Springer. doi: http://dx.doi.org/10.1007/978-3-319-56333-6 17.

Winner, L. (1980). 'Do artifacts have politics?' Daedalus: 121-136.

Wrzesniewski, A. and J. E. Dutton (2001). 'Crafting a job: Revisioning employees as active crafters of their work.' Academy of management review 26(2): 179-201. doi: http://dx. doi.org/10.5465/AMR.2001.4378011.

\section{End notes}

1 Several authors have traced globally successful team concepts back to Tavistock and the Industrial Democracy Experiments (See Mumford, 1997; Deutsch, 2005).

2 It is worth noting that the concept of «technology» is not reduced to merely physical machines. The concept, is rooted in 'techne' and 'logos', and besides physical parts, it also contain methods, routines and techniques, and the knowledge of production of objects and services. Thus, 'technology' or the technical system becomes a system that structures the way the people of the social system work and interact. But the social system also restructures the system. Although 'joint optimization' may struck one as a very 'modern' notion, the STS dual perspective on the technical system seems to align well with Giddens' structuration theory (Knutstad et al., 2009).

3 See Gustavsen's discussion of Emery in this issue.

${ }^{4}$ As pointed out in Knutstad et al., 2009.

5 See Morgan, 1986.

6 The term cogenerative learning in relation to this field was first used by Elden and Levin, 1991.

7 The amount of studies of technology and change in organizations is vast. See, e.g., Chandler, 1973; Latour, 1987; Smith \& Marx, 1994. 